\title{
FITOTECNIA
}

\section{ENVELHECIMENTO DE RESÍDUOS VEGETAIS SOBRE O SOLO E OS REFLEXOS NA EFICÁCIA DE HERBICIDAS APLICADOS EM PRÉ-EMERGÊNCIA ( $\left.{ }^{1}\right)$}

\author{
NÚBIA MARIA CORREIA $\left({ }^{2 *}\right)$; JULIO CEZAR DURIGAN $\left({ }^{2}\right)$; WANDERLEY JOSÉ DE MELO $\left({ }^{3}\right)$
}

\begin{abstract}
RESUMO
Com o objetivo de avaliar os efeitos do envelhecimento dos resíduos vegetais de diferentes espécies [sorgo de cobertura (Sorghum bicolor x S. sudanensis 'Cober Exp'), milheto forrageiro (Pennisetum americanum 'BN2'), capim-pé-de-galinha (Eleusine coracana) e capim-braquiária (Brachiaria brizantha)], no controle de Ipomoea grandifolia, pelos herbicidas diclosulam e imazaquin, aplicados em pré-emergência, foi desenvolvido experimento em casa de vegetação, no período de agosto a dezembro de 2004. Foram realizadas determinações químicas nos materiais vegetais em decomposição. A eficácia do herbicida diclosulam não foi afetada pelo envelhecimento da palha de nenhuma das coberturas estudadas. Pelo contrário, a associação desse herbicida a qualquer dos resíduos vegetais estudados, principalmente o de capimbraquiária, favoreceu o controle da planta daninha. O imazaquin teve o potencial de controle influenciado pelas coberturas de milheto forrageiro e capim-braquiária, aos 90 dias após a deposição dos resíduos vegetais sobre o solo. Tal comportamento pode ser atribuído ao enriquecimento de celulose e lignina nos materiais vegetais de milheto forrageiro e capim braquiária.
\end{abstract}

Palavras-chave: constituição química, decomposição, Ipomoea grandifolia, palha, sistema de semeadura direta, herbicidas residuais

\section{ABSTRACT \\ CROP RESIDUES AGING ON SOIL AND THEIR EFFECTS ON PRE-EMERGENCE HERBICIDES}

An experiment was conducted from August to December 2004 under greenhouse conditions to evaluate the effects of aging residues of different plant species [coverage sorghum (Sorghum bicolor $x$ S. sudanensis 'Cober Exp'), forage millet (Pennisetum americanum 'BN2'), finger millet (Eleusine coracana) and St. Lucia Grass (Brachiaria brizantha)], on the control of Ipomoea grandifolia using the pre-emergence herbicides diclosulam and imazaquin. Crop residues were subjected to chemical analyses. The efficiency of diclosulam was not affected by any of the residues. On the other hand, in association with residues of any of the species, but especially with St. Lucia Grass, this herbicide showed increased weed control efficiency. The control potential of imazaquin was influenced by forage millet and St Lucia Grass residues 90 days after laying residues on the soil. This behavior may be due to cellulose and lignin increase in both forage millet and St. Lucia Grass.

Key words: chemical constitution, decomposition, Ipomoea grandifolia, straw, no-tillage, residual herbicides.

(1) Recebido para publicação em 7 de novembro de 2005 e aceito em 17 de agosto de 2006.

$\left({ }^{2}\right)$ Departamento de Fitossanidade, Universidade Estadual Paulista (UNESP). Via de Acesso Prof. Paulo Donato Castellane, s/n. 14884-900 Jaboticabal (SP), Brasil. E-mail: correianm@fcav.unesp.br *Autora correspondente; jcdurigan@fcav.unesp.br

$\left({ }^{3}\right)$ Departamento de Tecnologia, UNESP. Campus de Jaboticabal (SP), Brasil. E-mail: wjmelo@fcav.unesp.br 


\section{INTRODUÇÃO}

No sistema de semeadura direta, devido ao não-revolvimento do solo, os resíduos vegetais das culturas anteriores e das plantas daninhas ficam sobre o terreno, formando o que se designa por cobertura morta. Essa cobertura pode comprometer a capacidade de um herbicida residual em atingir o solo, devido a sua retenção. Dependendo das características físico-químicas dos herbicidas, como solubilidade, pressão de vapor e polaridade, a palha terá maior ou menor influência na sua eficácia (Rodrigues, 1993). A quantidade e o período em que ocorrem as chuvas após a aplicação, também podem influenciar na retenção dos herbicidas.

O tipo de cobertura (vegetação espontânea, ervilhaca-peluda e trigo) influenciou na interceptação do herbicida fluometuron e na sua lixiviação até o solo, possivelmente por diferenças na quantidade de biomassa produzida e acumulada sobre o solo e na constituição química dos resíduos (GASTON et al., 2001). Em outro trabalho, o controle das espécies de plantas daninhas Brachiaria plantaginea, Euphorbia heterophylla e Bidens pilosa pelo herbicida imazaquin não foi comprometido pela presença de 7 e $14 \mathrm{t} \mathrm{ha}^{-1}$ de palha de aveia-preta sobre o solo. Ao contrário, a cobertura morta contribuiu para o controle das plantas daninhas, possibilitando, até mesmo, redução da dosagem recomendada de imazaquin (RodRIGUES et al., 2000).

Após a aplicação do herbicida atrazine, grande parte do produto foi retida pela palha de canade-açúcar depositada sobre o solo (Selim et al., 2003). No entanto, em virtude da sua lixiviação pela água da chuva, parte do herbicida atingiu a superfície do solo com o decorrer do tempo. Nesse mesmo trabalho, uma semana após a aplicação, cerca de $22 \%$ do atrazine ainda permanecia na palha, mesmo após precipitação pluvial acumulada de $23 \mathrm{~mm}$. O mesmo ocorreu para os herbicidas pendimethalin e metribuzin. Além disso, a presença da palha foi altamente benéfica para evitar perdas por escorrimento superficial dos herbicidas aplicados. Contudo, para o trifluralin, apenas traços do herbicida foram detectados no solo e na palha de aveia-preta, mesmo após irrigação de $20 \mathrm{~mm}$ (RodRIGUEs et al., 1998). Os autores atribuíram o ocorrido, possivelmente, à rápida fotodecomposição e volatilização do herbicida na palha, impedindo-o de atingir o solo e ser incorporado pela água de irrigação.

Mudanças na constituição química dos resíduos vegetais durante o seu processo de decomposição podem ser responsáveis pela capacidade diferenciada de adsorção dos herbicidas.
O aumento da adsorção na cobertura morta em deterioração pode estar associado ao enriquecimento de lignina. Em condição de fraca afinidade, os herbicidas podem ser removidos seguindo o fluxo da água (DAO, 1991).

A fragmentação da palha, decorrente da sua deterioração, pode resultar em acréscimos na adsorção de herbicidas, devido ao aumento na sua superfície de contato. $\mathrm{O}$ aprisionamento ou absorção física das moléculas do herbicida dentro de estruturas da parede celular, como as microfibrilas de celulose embebidas na matriz de lignina-hemicelulose, também pode favorecer o aumento na capacidade de adsorção (DAO, 1991; REDDY et al., 1997).

Quando aplicado sobre resíduos vegetais secos envelhecidos e resíduos frescos recém-cortados, apenas $52 \%$ e $32 \%$ do herbicida atrazine conseguiram atingir o solo, respectivamente (SIGUA et al., 1993). Para os autores, o mecanismo responsável pela redução na remoção de herbicidas em resíduos frescos pode estar relacionado à sua maior hidrofobicidade.

Com o envelhecimento de resíduos vegetais de azevém houve aumento na adsorção do herbicida cyanazine (REDDY et al., 1997). O mesmo foi observado para o herbicida chlorimuron-ethyl e as palhas de centeio e ervilhaca-peluda (REDDY et al., 1995). Nesse caso, constatou-se maior retenção do herbicida nos resíduos de ervilhaca-peluda, justificada, segundo os autores, pelas diferenças físicas e químicas entre o material vegetal.

As mudanças no sistema de produção de determinadas culturas são acompanhadas do surgimento de dificuldades que precisam ser contornadas e/ou esclarecidas em trabalhos científicos. Os efeitos da palha de diferentes espécies utilizadas como cobertura no sistema de semeadura direta, em função do seu envelhecimento e possíveis modificações na sua constituição química, sobre a eficácia de herbicidas aplicados em pré-emergência, são exemplos dessas dúvidas.

O presente trabalho objetivou avaliar os efeitos do envelhecimento e das mudanças na constituição química de resíduos vegetais de diferentes espécies, na eficácia de herbicidas residuais aplicados em préemergência, visando ao controle de Ipomoea grandifolia.

\section{MATERIAL E MÉTODOS}

O experimento foi desenvolvido no período de agosto a dezembro de 2004, em casa de vegetação, do Departamento de Fitossanidade, da Universidade Estadual Paulista, Campus de Jaboticabal (SP). 
O delineamento experimental utilizado foi o inteiramente casualizado, no esquema fatorial $5 \times 4$ x $2+1$, com quatro repetições. Os níveis dos fatores foram constituídos por: palhas oriundas de quatro espécies utilizadas como cobertura [sorgo de cobertura (Sorghum bicolor $x$ S. sudanensis 'Cober Exp'), milheto forrageiro (Pennisetum americanum 'BN2'), capim-péde-galinha (Eleusine coracana) e capim-braquiária (Brachiaria brizantha)] e um tratamento sem palha; quatro épocas de coleta de palha (zero, 30, 60 e 90 dias após a deposição dos resíduos vegetais na superfície do solo); a aplicação, em pré-emergência, dos herbicidas diclosulam ( $\left.35 \mathrm{~g} \mathrm{ha}^{-1}\right)$ e imazaquin (140 g $\mathrm{ha}^{-1}$ ). Além disso, manteve-se uma testemunha como tratamento adicional, sem cobertura e não tratada com os herbicidas.

As culturas de coberturas foram instaladas na primeira semana de março de 2004, em condições de campo, na Fazenda Três Marcos, localizada em Uberlândia (MG). As semeaduras do milheto forrageiro, capim-pé-de-galinha e capim-braquiária foram feitas a lanço, nas densidades de 25,15 e 18 $\mathrm{kg} \mathrm{ha}^{-1}$ respectivamente. O sorgo foi semeado em linha, com $0,25 \mathrm{~m}$ de distância entre linhas, permanecendo 10 plantas por metro ou $400 \mathrm{mil}$ plantas $\mathrm{ha}^{-1}$.

As culturas foram cortadas e esparramadas sobre o solo manualmente, no fim do mês de julho. A partir da deposição, a palha remanescente sobre o solo foi coletada nas quatro épocas estipuladas e encaminhada à casa de vegetação, onde se procedeu ao término da sua secagem.

Cada unidade experimental foi constituída por um vaso plástico com $21,50 \mathrm{~cm}$ de diâmetro e capacidade para três litros de solo. Como substrato, utilizou-se a mistura solo, areia e esterco, na proporção 3:1:0,5 respectivamente. Os resultados da análise química do substrato foram: $\mathrm{pH}$ (em água) 6,7; $\mathrm{P}$ (Mehlich 1) 120,6 $\mathrm{mg} \mathrm{dm}^{-3} ; \mathrm{K}, \mathrm{Ca}, \mathrm{Mg}$ e Al trocáveis $4,6,32,0,19,0$ e $0,0 \mathrm{mmol}_{\mathrm{c}} \mathrm{dm}^{-3}$, respectivamente; saturação por bases $79 \%$; matéria orgânica $31 \mathrm{~g} \mathrm{dm}^{-}$ ${ }^{3}$. O Latossolo Vermelho-Escuro distroférrico, textura argilosa, foi coletado na camada de $0-20 \mathrm{~cm}$ do perfil do solo e peneirado em malha de $5 \mathrm{~mm}$.

A planta daninha teste utilizada foi Ipomoea grandifolia, escolhida devido à ausência de efeito da palha de cana-de-açúcar na emergência dessa espécie (Correia e Durigan, 2004). Foram semeadas, por vaso, $1,22 \mathrm{~g}$ de sementes, distribuídas homogeneamente na superfície e incorporadas até um centímetro de profundidade. Após a semeadura, cada vaso recebeu a palha correspondente a cada espécie de cobertura e época de coleta estudada, depositada em camada uniforme e em quantidade equivalente a $6 \mathrm{tha}^{-1}$. A palha foi cortada em fragmentos menores, com tamanho igual ou inferior ao diâmetro do vaso.

Os herbicidas diclosulam e imazaquin foram aplicados logo após a deposição da palha sobre o solo do vaso, utilizando-se pulverizador costal, à pressão constante (mantida pelo $\mathrm{CO}_{2}$ comprimido) de $1,25 \mathrm{kgf}$ $\mathrm{cm}^{-2}$, munido de barra com um bico de jato plano ("leque") de deposição uniforme 80.03 e consumo de calda equivalente a $200 \mathrm{~L} \mathrm{ha}^{-1}$. Os valores das temperaturas do ar e do substrato, da umidade relativa do ar e as condições de vento, no momento das aplicações, encontram-se na Tabela 1.

Logo após a aplicação dos herbicidas foi realizada irrigação por aspersão, com auxílio de um regador, sendo aplicada uma lâmina de $20 \mathrm{~mm}$, cobrindo uniformemente a superfície de todos os vasos, a fim de favorecer a lixiviação dos herbicidas da palha para o solo. No decorrer do experimento, sempre que necessário, a irrigação foi realizada com o propósito de manter a capacidade de campo do solo próxima a $75 \%$. A água foi adicionada próxima à borda do vaso, evitando molhar a superfície da palha.

Foi avaliado o número de plântulas emergidas de I. grandifolia aos 14, 28 e 42 dias após a aplicação (DAA) dos herbicidas, sendo consideradas emergidas as plântulas visíveis em cada avaliação, com mais de $0,5 \mathrm{~cm}$ de parte aérea acima da camada de palha. Aos 42 DAA, as plantas foram cortadas rente ao solo, acondicionadas em sacos de papel e levadas à estufa com circulação forçada de ar, a $65{ }^{\circ} \mathrm{C}$, até massa constante, quando foram pesadas.

No momento da coleta dos resíduos vegetais remanescentes sobre o solo, nas quatro épocas estipuladas, amostrou-se uma quantidade de palha, que foi acondicionada em sacos de papel e levada à estufa com circulação forçada de ar a $50^{\circ} \mathrm{C}$, até massa constante. Posteriormente, essas amostras foram moídas em moinho Wiley equipado com peneira de 40 mesh. Nesses materiais, foram determinados os teores de carbono total (DABIN, 1976), nitrogênio total (MELO, 1977), hemicelulose, celulose e lignina (VAN SOEST, 1967). As análises foram realizadas no Laboratório de Bioquímica do Solo, do Departamento de Tecnologia, da Universidade Estadual Paulista, Campus de Jaboticabal (SP).

Os dados obtidos foram submetidos ao teste F na análise de variância e, quando significativo $(p<0,01$ ou $p<0,05)$, os efeitos das coberturas e dos herbicidas residuais foram comparados com o auxílio do teste de Tukey a $5 \%$ de probabilidade. Os efeitos das épocas de coleta, quando significativos, foram submetidos à análise de regressão. 
Tabela 1. Temperaturas do ar e do substrato, umidade relativa do ar e condições de vento, no momento das aplicações dos herbicidas. UNESP, Campus de Jaboticabal (SP), 2004

\begin{tabular}{llll}
\hline \multirow{2}{*}{ Aplicações } & \multicolumn{2}{c}{ Temperatura } & Umidade relativa do ar \\
\cline { 2 - 3 } & Ar Condições de vento \\
\hline
\end{tabular}

Primeira

$(6 / 8 / 2004)$

Segunda

$(5 / 9 / 2004)$

Terceira

(5/10/2004)

Quarta

$(4 / 11 / 2004)$
29,7

28,7
24,5

27,2

28,4

26,9
61

51

56
Brisa suave

Brisa suave

Brisa suave

Brisa suave

\section{RESULTADOS E DISCUSSÃO}

A interação entre tipos de cobertura, herbicidas e épocas de coleta de palha foi significativa para todas as avaliações de contagem de plântulas e para matéria seca de plantas. Para melhor entendimento e atendendo diretamente ao objetivo proposto, optou-se pelo desdobramento de coberturas dentro das combinações entre herbicidas e épocas de coleta, e pelo desdobramento de épocas dentro das combinações de herbicidas e tipos de cobertura.

Para as avaliações de emergência de plântulas e matéria seca das aos $42 \mathrm{DAA}$, não houve diferença significativa entre as coberturas tratadas com o herbicida diclosulam, inicialmente, e aos 30 e 60 dias após a deposição (DAD) da palha na superfície do solo (Tabela 2). No entanto, aos 90 DAD, as coberturas diferiram entre si, com maior número de plântulas emergidas no tratamento sem cobertura do solo e menor na palha de capim-braquiária, embora aos 14 DAA não houve diferença significativa entre os resíduos vegetais. Nessa época de deposição, as coberturas não influenciaram no acúmulo de massa da planta daninha.

Pelos resultados verificou-se que o diclosulam, independentemente da cobertura e do envelhecimento da palha, não teve o potencial de controle da espécie Ipomoea grandifolia afetado. Provavelmente, o herbicida não ficou retido na palha e os $20 \mathrm{~mm}$ de irrigação foram suficientes para removêlo até o solo. Pelo contrário, a associação deste herbicida a qualquer dos resíduos vegetais estudados, principalmente o de capim-braquiária, favoreceu o controle da planta daninha.

A palha mantida sobre o solo pode afetar a emergência das plantas daninhas por três processos distintos, o físico, o biológico e o químico, com possíveis interações entre eles (Pitelli e Durigan, 2001). O efeito físico é importante para sementes fotoblásticas positivas e para aquelas que necessitem de grande amplitude térmica para iniciar o processo germinativo (Buzatti, 1999; Theisen e Vidal, 1999; Pitelli e Durigan, 2001). Além disso, o efeito físico da palha reduz as chances de sobrevivência das plântulas com pequena quantidade de reservas nas sementes. A presença da palha pode beneficiar algumas ações biológicas, pois cria condições para instalação de uma densa e diversificada microbiocenose na camada superficial do solo. De maneira geral, os microrganismos exercem importantes funções na deterioração e perda de viabilidade dos diversos tipos de diásporos no solo (Pitelli e Durigan, 2001). Os efeitos químicos estão relacionados com fenômenos alelopáticos, alterações na relação carbono nitrogênio $(C / N)$, imobilização e reciclagem de nutrientes.

Para o herbicida imazaquin, de modo geral, nas avaliações de emergência e matéria seca de plantas não houve significância para as coberturas, aos zero, 30 e 60 DAD (Tabela 3). Contudo, na primeira época de deposição, aos 28 e 42 DAA, o tratamento sem cobertura resultou em maior número de plântulas emergidas. Aos $30 \mathrm{DAD}$, verificou-se menor matéria seca de plantas de I. grandifolia quando não foi feita a cobertura do solo, diferindo significativamente das plantas crescidas sobre palha de capim-braquiária, com maior acúmulo de massa.

Aos 90 DAD foram constatadas diferenças entre as coberturas em todas as avaliações realizadas. Aos 14, 28 e 42 DAA, a palha de milheto forrageiro propiciou maior número de plântulas emergidas, diferindo significativamente do tratamento sem 
cobertura. O mesmo foi observado para acúmulo de matéria seca, cujas palhas de milheto forrageiro e capim-braquiária promoveram as maiores médias, diferindo do tratamento sem cobertura, que não diferiu apenas da cobertura de capim-pé-de-galinha. Todavia, o maior acúmulo de massa, observado nas palhas de milheto forrageiro e capim-braquiária, torna-se pequeno, pois apesar do aumento médio de $83 \%$ em relação ao tratamento sem cobertura (mas tratado com imazaquin), comparadas à testemunha não pulverizada com o herbicida e mantida com solo nu, teve-se, em média, uma redução de $94 \%$. Comparado a ela, o tratamento sem cobertura resultou em decréscimo de 96,6\% na matéria seca das plantas de I. grandifolia, correspondendo a um aumento relativo de $2,6 \%$ para as coberturas de milheto forrageiro e capim-braquiária.

A eficácia do herbicida imazaquin foi afetada, mesmo que em pequena proporção, pelo envelhecimento da palha de milheto forrageiro e capim-braquiária, com resultados significativos aos $90 \mathrm{DAD}$, época em que é feita a aplicação deste herbicida em condições de campo na cultura da soja. Possivelmente, parte do herbicida ficou retida a estas coberturas e os $20 \mathrm{~mm}$ de irrigação não foram suficientes para promover sua total remoção das coberturas, influenciando no potencial de controle da planta daninha, com decréscimos não muito pronunciados.

Como foi utilizado neste estudo a quantidade de palha equivalente $\mathrm{a} 6 \mathrm{t}$ ha ${ }^{-1}$, padrão para todas as épocas e coberturas, admite-se especular que maiores níveis de milheto forrageiro e capim-braquiária, assim como períodos maiores a 90 DAD, podem comprometer de forma mais expressiva o controle de I. grandifolia pelo herbicida imazaquin.

Quanto ao desdobramento de épocas dentro das combinações de herbicidas e coberturas, a tendência observada foi que, para os dois herbicidas estudados, houve aumento na emergência de plântulas de $I$. grandifolia, refletindo na matéria seca, com o decorrer da época de coleta de palha, como pode ser verificada nas equações de regressão descritas nas tabelas 2 e 3 . No entanto, tal processo ocorreu para todas as coberturas, inclusive para o tratamento mantido com solo nu. Dessa forma, não se pode atribuir o aumento observado ao envelhecimento das palhas e, sim, a possíveis modificações nas condições térmicas e fotoperiódicas, visto que a quantidade e qualidade das sementes da planta daninha, o substrato utilizado e as irrigações iniciais e de manutenção foram as mesmas em todas as etapas de instalação do experimento.

Quanto às mudanças na constituição dos resíduos vegetais em diferentes épocas, a partir de sua deposição sobre o solo, houve efeito significativo dos tipos de cobertura, das épocas de amostragem e da interação entre eles, em todas as características avaliadas.
Em todas as épocas de coleta, os maiores teores de carbono total foram determinados na palha de sorgo, não diferindo significativamente de capimbraquiária nas três últimas coletas (Tabela 4). Ao se desdobrar os efeitos das épocas de coleta para cada cobertura (Figura 1), observou-se que a concentração de carbono da palha de milheto forrageiro não foi influenciada pelo envelhecimento dos seus resíduos vegetais. Todavia, a percentagem na palha de capimpé-de-galinha reduziu linearmente com o tempo, revelando que o teor mais elevado ocorreu no início das coletas. Para sorgo e capim-braquiária, o ajuste mais adequado dos dados foi o polinomial, com maiores reduções de carbono aos $30 \mathrm{DAD}$, para a palha de sorgo e, na primeira coleta, para capimbraquiária.

Aos 60 DAD, não foi constatada diferença significativa entre as coberturas para teor de nitrogênio total. Nas demais épocas, a palha de capimbraquiária foi responsável pelas maiores concentrações, não diferindo significativamente de capim-pé-de-galinha, inicialmente e aos 90 DAD (Tabela 4). Com o decorrer do tempo, os teores de nitrogênio das palhas de milheto forrageiro e capimpé-de-galinha não foram afetados pelo envelhecimento. Contudo, para as coberturas de sorgo e capim-braquiária as porcentagens oscilaram ao longo da permanência dos resíduos sobre o solo, com melhor ajuste dos dados na forma polinomial. As maiores reduções de nitrogênio foram observadas aos 90 DAD, para a palha de sorgo, e aos 60 e 90 DAD, para a de capim-braquiária (Figura 1).

Nas três primeiras avaliações, os maiores teores de hemicelulose ocorreram na palha de capimbraquiária. No entanto, aos $90 \mathrm{DAD}$, não houve diferença significativa entre os resíduos vegetais (Tabela 4). Com o passar do tempo, verificou-se, aos 90 DAD, os menores teores de hemicelulose nas palhas de sorgo e capim-braquiária, com ajuste polinomial dos dados. O envelhecimento das palhas de milheto forrageiro e capim-pé-de-galinha não afetou as concentrações de hemicelulose delas (Figura 1).

Independentemente da época, nas palhas de sorgo e milheto forrageiro ocorreram as maiores concentrações de celulose (Tabela 4). O envelhecimento da palha de capim-pé-de-galinha resultou em aumento linear da concentração de celulose pelos seus resíduos, enquanto as demais tiveram os dados ajustados na forma polinomial (Figura 1). Os maiores teores de celulose foram obtidos aos $90 \mathrm{DAD}$, com aumentos percentuais de $62 \%$ para a palha de capim-pé-de-galinha, $31 \%$ para sorgo, $23 \%$ para capim-braquiária e $7 \%$ para milheto forrageiro, em relação aos valores iniciais (Tabela 4). 
Tabela 2. Número de plântulas emergidas de Ipomoea grandifolia aos 14, 28 e 42 dias após a aplicação (DAA) e matéria seca de plantas (g vaso $\left.{ }^{-1}\right)$, tratadas com o herbicida diclosulam, aplicado em pré-emergência sobre cinco tipos de cobertura, em quatro épocas de coleta de palha. UNESP, Campus de Jaboticabal (SP), 2004

\begin{tabular}{|c|c|c|c|c|c|c|}
\hline \multirow{2}{*}{ Avaliações } & \multirow{2}{*}{ Tipos de cobertura } & \multicolumn{4}{|c|}{ Dias após a deposição da palha } & \multirow{2}{*}{ Equações de regressão } \\
\hline & & Zero & 30 & 60 & 90 & \\
\hline \multirow{7}{*}{14 DAA } & Sorgo & 16,25 & 27,25 & 26,75 & 35,75 a & $y=0,193 x+17,800 R^{2}=0,88^{* *}$ \\
\hline & Milheto forrageiro & 14,25 & 20,75 & 28,50 & 39,50 a & $y=0,278 x+13,225 R^{2}=0,98^{* *}$ \\
\hline & Capim-pé-de-galinha & 18,50 & 23,50 & 32,25 & 40,25 a & $y=0,247 x+17,525 R^{2}=0,99^{* *}$ \\
\hline & Capim-braquiária & 11,00 & 20,50 & 26,50 & 29,50 a & $y=0,205 x+12,650 R^{2}=0,95^{* *}$ \\
\hline & Sem cobertura do solo & 16,75 & 26,50 & 34,00 & $54,75 \mathrm{~b}$ & $y=0,405 x+14,775 R^{2}=0,94^{* *}$ \\
\hline & DMS & \multicolumn{4}{|c|}{12,71} & \\
\hline & Test. s/ palha e s/ herb. ${ }^{(1)}$ & 21,25 & 24,25 & 28,00 & 65,25 & \\
\hline \multirow{7}{*}{$28 \mathrm{DAA}$} & Sorgo & 19,50 & 28,75 & 24,50 & $32,50 \mathrm{~b}$ & Não significativo \\
\hline & Milheto forrageiro & 15,50 & 23,75 & 27,00 & $37,00 \mathrm{bc}$ & $y=0,226 x+15,650 R^{2}=0,97^{* *}$ \\
\hline & Capim-pé-de-galinha & 16,50 & 17,75 & 23,50 & $33,25 \mathrm{~b}$ & $y=0,187 x+14,350 R^{2}=0,90 * *$ \\
\hline & Capim-braquiária & 9,50 & 19,50 & 21,75 & $15,50 \mathrm{a}$ & Não significativo \\
\hline & Sem cobertura do solo & 21,00 & 26,75 & 30,75 & $49,00 \mathrm{c}$ & $y=0,293 x+18,675 R^{2}=0,88^{* *}$ \\
\hline & DMS & \multicolumn{4}{|c|}{13,06} & \\
\hline & Test. s/ palha e s/ herb. & 26,75 & 24,00 & 25,25 & 59,25 & \\
\hline \multirow{7}{*}{$42 \mathrm{DAA}$} & Sorgo & 16,50 & 23,25 & 18,50 & $24,50 \mathrm{~b}$ & Não significativo \\
\hline & Milheto forrageiro & 14,25 & 20,50 & 21,50 & $30,50 \mathrm{bc}$ & $y=0,166 x+14,225 R^{2}=0,92 * *$ \\
\hline & Capim-pé-de-galinha & 8,00 & 11,50 & 10,75 & $27,75 \mathrm{~b}$ & $y=0,195 x+5,725 R^{2}=0,71^{* *}$ \\
\hline & Capim-braquiária & 0,25 & 18,75 & 15,00 & $9,00 \mathrm{a}$ & Não significativo \\
\hline & Sem cobertura do solo & 17,25 & 20,00 & 16,75 & $44,75 \mathrm{c}$ & $y=0,007 x^{2}-0,367 x+19,113 R^{2}=0,88^{* *}$ \\
\hline & \multicolumn{5}{|l|}{$\begin{array}{l}\text { Sem cobertura do solo } \\
\text { DMS }\end{array}$} & \\
\hline & Test. s/ palha e s/ herb. & 29,25 & 23,75 & 27,00 & 65,50 & \\
\hline \multirow{7}{*}{$\begin{array}{l}\text { Matéria seca } \\
\text { de plantas } \\
\text { aos } 42 \text { DAA }\end{array}$} & Sorgo & 0,19 & 0,38 & 0,29 & 0,36 & Não significativo \\
\hline & Milheto forrageiro & 0,18 & 0,40 & 0,34 & 0,54 & Não significativo \\
\hline & Capim-pé-de-galinha & 0,09 & 0,17 & 0,15 & 0,48 & Não significativo \\
\hline & Capim-braquiária & 0,12 & 0,31 & 0,22 & 0,67 & $y=0,005 x+0,099 R^{2}=0,71^{* *}$ \\
\hline & Sem cobertura do solo & 0,19 & 0,24 & 0,20 & 0,69 & $y=0,0001 x^{2}-0,006 x+0,221 R^{2}=0,88^{* *}$ \\
\hline & DMS & \multicolumn{4}{|c|}{0,44} & \\
\hline & Test. s/ palha e s/ herb. & 9,11 & 13,54 & 20,59 & 36,96 & \\
\hline
\end{tabular}

Médias seguidas pela mesma letra não diferem significativamente entre si pelo teste de Tukey a $5 \%$ de probabilidade. $\left({ }^{1}\right)$ Testemunha sem palha e sem herbicida. **, ${ }^{*}$ Significativo pelo teste $\mathrm{F}$ ao nível de $1 \%$ e $5 \%$ de probabilidade respectivamente.

Para lignina, obteve-se maior concentração na palha de milheto forrageiro, não diferindo de sorgo, inicialmente e aos 90 DAD e, também, de capimbraquiária, aos 90 DAD (Tabela 4). Para todos os tipos de cobertura, o maior acúmulo de lignina foi obtido aos $90 \mathrm{DAD}$, com ajuste mais adequado dos dados na forma polinomial (Figura 1). Os acréscimos de lignina foram de $190 \%$ para capim-braquiária, $84 \%$ para capim-pé-de-galinha, $31 \%$ para sorgo e $28 \%$ para milheto forrageiro, comparados aos teores quantificados inicialmente (Tabela 4).

Com algumas exceções, observadas para capim-pé-de-galinha, a dinâmica das concentrações de carbono total, nitrogênio total, hemicelulose, celulose e lignina não ocorreu de forma gradual ou linear ao longo do processo de envelhecimento das palhas. Os dados, pelo menos a maioria deles, oscilaram com o decorrer da permanência dos resíduos sobre o solo, com melhor ajuste na forma polinomial. Aos 90 DAD, época cujos resultados foram mais expressivos, obteve-se aumento dos teores de celulose e lignina (para todas as coberturas) e carbono total (para capim-braquiária), reduções de hemicelulose (para sorgo e capim-braquiária), carbono total (para sorgo e capim-pé-de-galinha) e nitrogênio total (para sorgo e capim-braquiária). O envelhecimento da palha, também, não afetou as concentrações de nitrogênio total e hemicelulose das palhas de milheto forrageiro e capim-pé-de-galinha, e de carbono total dos resíduos de milheto forrageiro (Figura 1). 
Tabela 3. Número de plântulas emergidas de Ipomoea grandifolia aos 14, 28 e 42 dias após a aplicação (DAA) e matéria seca de plantas $\left(\mathrm{g} \mathrm{vaso}^{-1}\right)$, tratadas com o herbicida imazaquin, aplicado em pré-emergência sobre cinco tipos de cobertura, em quatro épocas de coleta de palha. UNESP, Campus de Jaboticabal (SP), 2004.

\begin{tabular}{|c|c|c|c|c|c|c|}
\hline \multirow{2}{*}{ Avaliações } & \multirow{2}{*}{ Tipos de cobertura } & \multicolumn{4}{|c|}{ Dias após a deposição da palha } & \multirow{2}{*}{ Equações de regressão } \\
\hline & & Zero & 30 & 60 & 90 & \\
\hline \multirow{7}{*}{14 DAA } & Sorgo & 19,75 & 26,50 & 36,50 & $54,00 \mathrm{ab}$ & $y=0,376 x+17,275 R^{2}=0,95^{* *}$ \\
\hline & Milheto forrageiro & 22,00 & 25,75 & 26,75 & $63,25 \mathrm{~b}$ & $y=0,009 x^{2}-0,403 x+23,913 R^{2}=0,93 * *$ \\
\hline & Capim-pé-de-galinha & 21,25 & 20,50 & 32,50 & $53,75 \mathrm{ab}$ & $y=0,006 x^{2}-0,185 x+21,075 R^{2}=0,99^{* *}$ \\
\hline & Capim-braquiária & 16,00 & 19,25 & 28,75 & $52,00 \mathrm{ab}$ & $y=0,392 x+11,375 R^{2}=0,87^{* *}$ \\
\hline & Sem cobertura do solo & 25,75 & 25,25 & 28,75 & $50,00 \mathrm{a}$ & $y=0,006 x^{2}-0,290 x+26,438 R^{2}=0,94^{* *}$ \\
\hline & DMS & \multicolumn{4}{|c|}{12,71} & \\
\hline & Test. s/ palha e s/ herb. ${ }^{(1)}$ & 21,25 & 24,25 & 28,00 & 65,25 & \\
\hline \multirow{7}{*}{28 DAA } & Sorgo & $18,25 \mathrm{a}$ & 26,00 & 35,50 & $53,50 \mathrm{ab}$ & $y=0,384 x+16,025 R^{2}=0,96^{* *}$ \\
\hline & Milheto forrageiro & $25,50 \mathrm{ab}$ & 24,25 & 25,50 & $62,75 \mathrm{~b}$ & $y=0,011 x^{2}-0,586 x+27,175 R^{2}=0,95^{* *}$ \\
\hline & Capim-pé-de-galinha & $26,50 \mathrm{ab}$ & 21,25 & 33,00 & $52,00 \mathrm{ab}$ & $y=0,007 x^{2}-0,312 x+26,013 R^{2}=0,99^{* *}$ \\
\hline & Capim-braquiária & 16,25 a & 21,50 & 28,25 & $49,00 \mathrm{a}$ & $y=0,350 x+13,000 \quad R^{2}=0,89^{* *}$ \\
\hline & Sem cobertura do solo & $33,50 \mathrm{~b}$ & 25,25 & 27,00 & $49,50 \mathrm{a}$ & $y=0,008 x^{2}-0,603 x+34,038 R^{2}=0,98^{* *}$ \\
\hline & DMS & \multicolumn{4}{|c|}{13,06} & \\
\hline & Test. s/ palha e s/ herb. & 26,75 & 24,00 & 25,25 & 59,25 & \\
\hline \multirow{7}{*}{42 DAA } & Sorgo & 19,75 a & 25,75 & 38,50 & $57,25 \mathrm{ab}$ & $y=0,418 x+16,525 R^{2}=0,95^{* *}$ \\
\hline & Milheto forrageiro & $26,25 \mathrm{ab}$ & 24,25 & 28,75 & $68,50 \mathrm{~b}$ & $y=0,116 x^{2}-0,606 x+27,688 \quad R^{2}=0,97^{* *}$ \\
\hline & Capim-pé-de-galinha & $25,25 \mathrm{ab}$ & 21,25 & 34,25 & 52,50 a & $y=0,006 x^{2}-0,240 x+24,663 R^{2}=0,99^{* *}$ \\
\hline & Capim-braquiária & 16,75 a & 21,75 & 28,75 & $54,25 \mathrm{ab}$ & $y=0,398 x+12,450 R^{2}=0,86^{* *}$ \\
\hline & Sem cobertura do solo & $36,25 \mathrm{~b}$ & 22,00 & 25,75 & 51,25 a & $y=0,011 x^{2}-0,831 x+36,438 \quad R^{2}=0,99^{* *}$ \\
\hline & DMS & \multicolumn{4}{|c|}{15,11} & \\
\hline & Test. s/ palha e s/ herb. & 29,25 & 23,75 & 27,00 & 65,50 & \\
\hline \multirow{7}{*}{$\begin{array}{l}\text { Matéria seca } \\
\text { de plantas } \\
\text { aos } 42 \text { DAA }\end{array}$} & Sorgo & 0,48 & $0,74 \mathrm{ab}$ & 0,87 & $1,73 \mathrm{~b}$ & $y=0,013 x+0,374 \quad R^{2}=0,85^{* *}$ \\
\hline & Milheto forrageiro & 0,61 & $0,63 \mathrm{ab}$ & 0,63 & $2,37 \mathrm{c}$ & $y=0,0005 x^{2}-0,025 x+0,699 R^{2}=0,93 *$ \\
\hline & Capim-pé-de-galinha & 0,59 & 0,54 a & 0,80 & $1,66 \mathrm{ab}$ & $y=0,0003 x^{2}-0,011+0,601 R^{2}=0,99 * *$ \\
\hline & Capim-braquiária & 0,67 & $1,08 \mathrm{~b}$ & 0,67 & $2,29 \mathrm{c}$ & $y=0,0003 x^{2}-0,015 x+0,811 \quad R^{2}=0,77^{* *}$ \\
\hline & Sem cobertura do solo & 0,49 & 0,38 a & 0,43 & $1,27 \mathrm{a}$ & $y=0,0003 x^{2}-0,016 x+0,519 R^{2}=96 * *$ \\
\hline & DMS & \multicolumn{4}{|c|}{0,44} & \\
\hline & Test. s/ palha e s/ herb. & 9,11 & 13,54 & 20,59 & 36,96 & \\
\hline
\end{tabular}

Médias seguidas pela mesma letra não diferem significativamente entre si pelo teste de Tukey a $5 \%$ de probabilidade. $\left({ }^{1}\right)$ Testemunha sem palha e sem herbicida. **,* Significativo pelo teste $\mathrm{F}$ ao nível de $1 \%$ e $5 \%$ de probabilidade respectivamente.

Com base na dinâmica dos teores dos constituintes químicos dos resíduos vegetais em decomposição/envelhecimento, pemite-se inferir que o aumento nos teores de celulose e lignina das palhas de milheto forrageiro e capim-braquiária podem ter comprometido a eficácia do herbicida imazaquin, possivelmente pela maior afinidade do herbicida com a palha, acarretando na adsorção de parte do produto.

A celulose é um homopolissacarídeo, principal constituinte da parede celular, composto por moléculas de glicose em ligação glicosídica $\beta 1,4$. O arranjo molecular em cadeias paralelas longas e a densidade de compactação dão à celulose uma estrutura quase cristalina. Essa estrutura fibrosa não pode oferecer sítios de ligação, porém, pode favorecer o aprisionamento ou absorção física das moléculas do herbicida dentro de espaços obstruídos da parede celular (DAO, 1991). Quanto à lignina, trata-se de um derivado de fenilpropano, com composição variável conforme a espécie vegetal, incluindo unidades de guaiacil, siringil, cumaril, sinapil, entre outras, em ligação tipo áril éter.

Com a decomposição, elevam-se os teores de celulose e lignina nos materiais vegetais, e em processos mais avançados de deterioração, o enriquecimento de lignina ocorre em detrimento ao declínio de celulose (CARDOSO, 1992). No entanto, no período avaliado do presente trabalho, não se constatou redução na concentração de celulose. 
Tabela 4. Teores (\%) de carbono total (C), nitrogênio total (N), hemicelulose (HEM), celulose (CEL) e lignina (LIG), em percentagem, de quatro tipos de cobertura, em quatro épocas a partir da deposição dos resíduos vegetais sobre o solo. UNESP, Campus de Jaboticabal (SP), 2004

\begin{tabular}{|c|c|c|c|c|c|}
\hline \multirow{2}{*}{ CQ } & \multirow{2}{*}{ Tipos de cobertura } & \multicolumn{4}{|c|}{ Dias após a deposição da palha } \\
\hline & & Zero & 30 & 60 & 90 \\
\hline \multirow[t]{5}{*}{$\mathrm{C}$} & Sorgo & $51,57 \mathrm{~b}$ & $46,62 \mathrm{~b}$ & $47,83 \mathrm{~b}$ & $48,22 \mathrm{~b}$ \\
\hline & Milheto forrageiro & $44,20 \mathrm{a}$ & 42,30 a & 42,73 a & 41,48 a \\
\hline & Capim-pé-de-galinha & 44,98 a & $43,52 \mathrm{ab}$ & $42,05 \mathrm{a}$ & 40,99 a \\
\hline & Capim-braquiária & $42,25 \mathrm{a}$ & $46,61 \mathrm{~b}$ & $45,05 \mathrm{ab}$ & $46,14 \mathrm{~b}$ \\
\hline & DMS & \multicolumn{4}{|c|}{3,32} \\
\hline \multirow[t]{5}{*}{$\mathrm{N}$} & Sorgo & $1,16 \mathrm{a}$ & $0,99 \mathrm{a}$ & $1,15 \mathrm{a}$ & $0,64 \mathrm{a}$ \\
\hline & Milheto forrageiro & $1,25 \mathrm{a}$ & $1,00 \mathrm{a}$ & $1,15 \mathrm{a}$ & 0,98 a \\
\hline & Capim-pé-de-galinha & $1,49 \mathrm{ab}$ & $1,37 \mathrm{a}$ & $1,34 \mathrm{a}$ & $1,42 \mathrm{~b}$ \\
\hline & Capim-braquiária & $1,77 \mathrm{~b}$ & $1,94 \mathrm{~b}$ & $1,48 \mathrm{a}$ & $1,49 \mathrm{~b}$ \\
\hline & DMS & \multicolumn{4}{|c|}{0,44} \\
\hline \multirow[t]{5}{*}{ HEM } & Sorgo & $33,38 \mathrm{a}$ & $31,96 \mathrm{a}$ & $33,31 \mathrm{a}$ & $30,83 \mathrm{a}$ \\
\hline & Milheto forrageiro & 35,36 a & 33,74 a & $35,30 \mathrm{a}$ & $33,33 \mathrm{a}$ \\
\hline & Capim-pé-de-galinha & $33,74 \mathrm{a}$ & 33,01 a & $34,74 \mathrm{a}$ & $32,07 \mathrm{a}$ \\
\hline & Capim-braquiária & $38,76 \mathrm{~b}$ & $42,40 \mathrm{~b}$ & $38,54 \mathrm{~b}$ & $32,85 \mathrm{a}$ \\
\hline & DMS & \multicolumn{4}{|c|}{2,61} \\
\hline \multirow[t]{5}{*}{ CEL } & Sorgo & $36,62 c$ & $38,89 \mathrm{~b}$ & $36,78 c$ & $47,85 \mathrm{~d}$ \\
\hline & Milheto forrageiro & $37,54 \mathrm{c}$ & $37,73 \mathrm{~b}$ & $37,48 \mathrm{c}$ & $40,05 \mathrm{c}$ \\
\hline & Capim-pé-de-galinha & $23,21 \mathrm{a}$ & $26,62 \mathrm{a}$ & $29,67 \mathrm{~b}$ & $37,69 \mathrm{~b}$ \\
\hline & Capim-braquiária & $27,41 \mathrm{~b}$ & 27,26 a & $26,89 \mathrm{a}$ & $33,76 \mathrm{a}$ \\
\hline & DMS & \multicolumn{4}{|c|}{2,14} \\
\hline \multirow[t]{5}{*}{ LIG } & Sorgo & $6,47 \mathrm{~b}$ & $5,58 \mathrm{~b}$ & $5,74 \mathrm{~b}$ & $8,44 \mathrm{~b}$ \\
\hline & Milheto forrageiro & $6,99 \mathrm{~b}$ & $7,20 \mathrm{c}$ & $6,84 \mathrm{c}$ & $8,92 \mathrm{~b}$ \\
\hline & Capim-pé-de-galinha & $3,76 \mathrm{a}$ & $3,29 \mathrm{a}$ & $3,32 \mathrm{a}$ & $6,94 \mathrm{a}$ \\
\hline & Capim-braquiária & $2,94 \mathrm{a}$ & $2,54 \mathrm{a}$ & $2,89 \mathrm{a}$ & $8,50 \mathrm{~b}$ \\
\hline & DMS & \multicolumn{4}{|c|}{0,93} \\
\hline
\end{tabular}

$\mathrm{CQ}=$ constituintes químicos.

Médias seguidas da mesma letra não diferem significativamente entre si pelo teste de Tukey a 5\% de probabilidade.

A degradação da celulose e de complexos celulose-lignina expõe superfícies de ligações adicionais, constituídas por grupos funcionais amino, amina, amido, fenólicos, alcoólicos e carboxílicos, associados ao nitrogênio e à lignina (DAO, 1991; REDDY et al., 1995), ocorrendo, assim, aumento na capacidade de troca cationnica (CTC) da palha em deterioração. Tais superfícies de ligação podem ser responsáveis pela maior adsorção de herbicidas em resíduos envelhecidos, principalmente para aqueles que, quando ionizados geram cargas positivas. Temse o conhecimento que o herbicida imazaquin possui caráter anfótero (LEITE et al., 1998), ou seja, reage como ácido ou como base dependendo do $\mathrm{pH}$. Em meio ácido há possibilidade de protonação da molécula, assumindo carga positiva, aumentando a sua adsorção em superfícies de alta CTC. Em meio alcalino, pode ser encontrado na forma aniônica da molécula. Na calda de pulverização, o imazaquin encontra-se na forma molecular, não ionizada. Todavia, após a sua aplicação e deposição na palha, pode haver a protonação de parte das moléculas do herbicida, aumentando a capacidade de adsorção do mesmo na palha envelhecida. 
Comparado ao herbicida metribuzin, houve maior adsorção do s-ethyl metribuzin $(99 \%$ de pureza) aos resíduos vegetais frescos e envelhecidos de trigo, possivelmente devido à sua menor solubilidade em água (DAO, 1991). Entretanto, em ambos constatou-se maior adsorção na palha

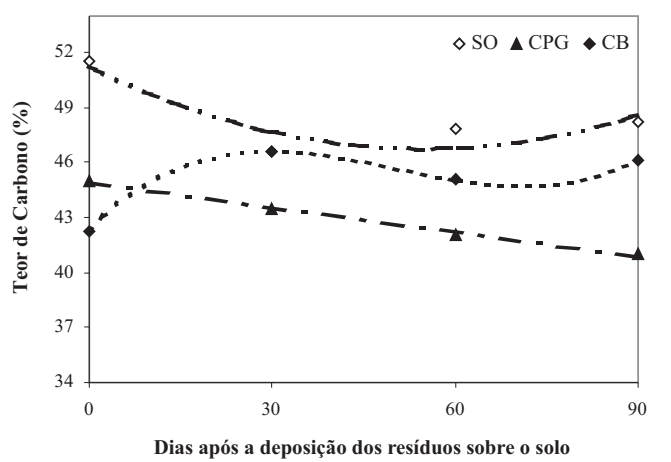

$\mathrm{y}_{\mathrm{SO}}=0,0015 \mathrm{x}^{2}-0,1631 \mathrm{x}+51,2228 * *\left(\mathrm{R}^{2}=0,82\right)$ $\mathrm{y}_{\mathrm{MF}}=42,68$

$\mathrm{y}_{\mathrm{CPG}}=-\mathbf{0 , 0 4 4 8 x}+44,9025 * *\left(R^{2}=0,99\right)$

$y_{C B}=0,000053 x^{3}-0,0081 x^{2}+0,3392 x+42,2475 *\left(R^{2}=1\right)$

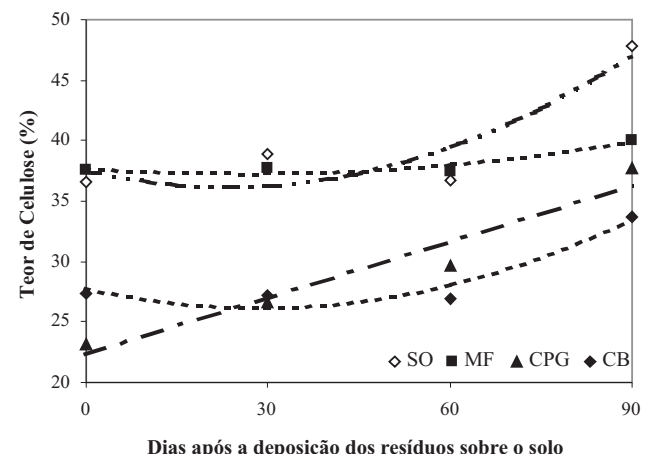

${ }_{S O}=0,0024 x^{2}-0,1148 x+37,50 * *\left(R^{2}=0,82\right)$ $\mathbf{y}_{\mathrm{MF}}=0,00066 \mathrm{x}^{2}-0,0354 \mathrm{x}+37,7030 * *\left(R^{2}=0,88\right)$ $\mathbf{y}_{\mathrm{CPG}}=0,1549 \mathrm{x}+22,3253 * *\left(R^{2}=0,94\right)$

$y_{C B}=0,0019 x^{2}-0,1134 x+27,7806 * *\left(R^{2}=0,91\right)$ envelhecida, atribuído às mudanças na constituição química dos resíduos durante a sua decomposição. O aumento da adsorção estava associado ao declínio da concentração de celulose ou reciprocamente com o enriquecimento de lignina da palha em deterioração.

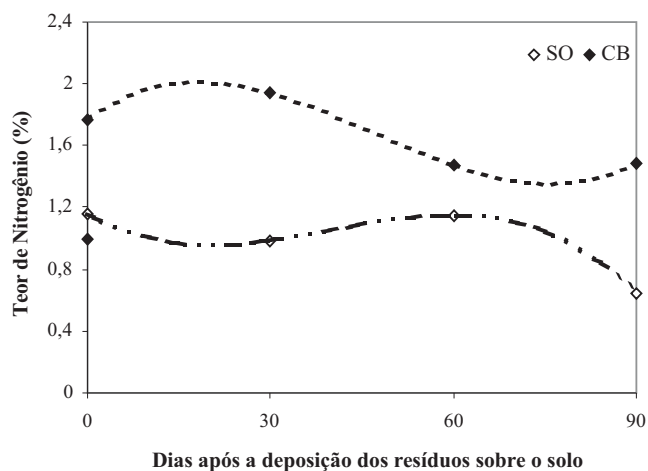

$y_{S O}=-0,000006 x^{3}+0,00075 x^{2}-0,0228 x+1,1625 *\left(R^{2}=1\right)$ $\mathrm{y}_{\mathrm{MF}}=1,09$ (NS)

$\mathrm{y}_{\mathrm{CPG}}=1,40$ (NS)

$y_{C B}=0,00007 x^{3}-0,00097 x^{2}+0,0288 x+1,7675^{*}\left(R^{2}=1\right)$

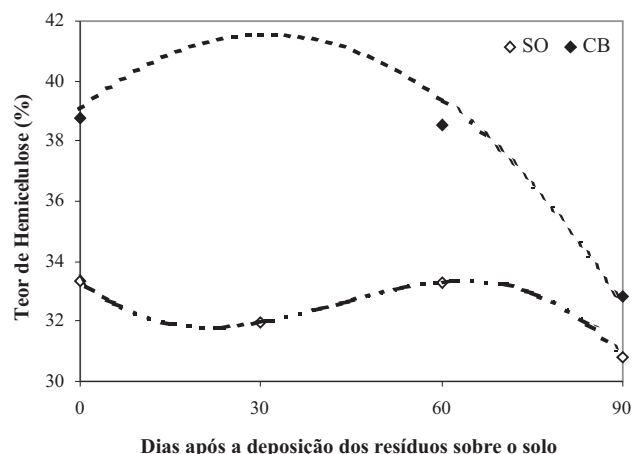

$\mathrm{y}_{\mathrm{SO}}=-0,000041 \mathrm{x}^{3}+0,0052 \mathrm{x}^{2}-0,1661 \mathrm{x}+33,3750 *\left(R^{2}=1\right)$ $\mathbf{y}_{\mathrm{MF}}=\mathbf{3 4 , 4 3}$ (NS)

$\mathrm{y}_{\mathrm{CPG}}=33,39$ (NS)

$\mathrm{y}_{\mathrm{CB}}=-0,002592 \mathrm{x}^{2}+0,1612 \mathrm{x}+39,0458 * *\left(\mathrm{R}^{2}=0,97\right)$

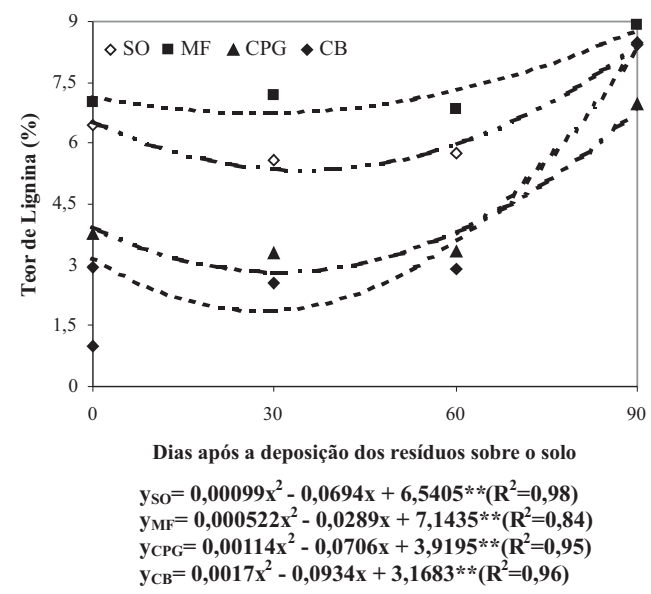

Figura 1. Teores de carbono, nitrogênio, hemicelulose, celulose e lignina, dos resíduos vegetais de sorgo (SO), milheto forrageiro $(\mathrm{MF})$, capim-pé-de-galinha (CPG) e capim-braquiária (CB), a partir da deposição da palha sobre o solo. UNESP, Campus de Jaboticabal (SP), 2004. 


\section{CONCLUSÕES}

1. A eficácia do herbicida diclosulam não foi afetada pelo envelhecimento da palha de nenhuma das coberturas estudadas.

2. O imazaquin teve o potencial de controle influenciado pelas coberturas de milheto forrageiro e capim-braquiária, aos 90 dias após a deposição dos resíduos vegetais sobre o solo, possivelmente, devido ao enriquecimento de celulose e lignina nestes materiais vegetais.

\section{REFERÊNCIAS}

BUZATTI, W. J. de S. Controle de plantas daninhas no sistema plantio direto na palha. In: PAULETTI, V; SEGANFREDO, R. Plantio direto: atualização tecnológica. São Paulo: Fundação Cargill/Fundação ABC, 1999. p. 97-111.

CARDOSO, E. J. B. N. Efeito da matéria orgânica na biologia do solo. In: ENCONTRO SOBRE MATÉRIA ORGÂNICA DO SOLO: PROBLEMAS E SOLUÇÕES, 1992, Botucatu. Anais... Botucatu: FCA/UNESP, 1992. p.37-62.

CORREIA, N. M.; DURIGAN, J. C. Emergência de plantas daninhas em solo coberto com palha de cana-de-açúcar. Planta Daninha, Viçosa, v.22, n.1, p.11-17, 2004.

DABIN, B. Curso sobre matéria orgânica do solo. Parte 1. Análise dos compostos húmicos do solo. Piracicaba: CENA, 1976. 115p.

DAO, T. H. Field decay of wheat straw and its effects on metribuzin and s-ethyl metribuzin sorption and elution from crop residue. Journal of Environmental Quality, Madison, v. 20, n. 1, p. 203-208, 1991.

GASTON, L. A.; BOQUET, D. J.; BOSCH, M. A. Fluometuron wash-off from cover crop residues and fate in a loessial soil. Soil Science, Baltimore, v. 166, n. 10, p. 681-690, 2001.

LEITE, C. R. F.; ALMEIDA, J. C. V. de; PRETE, C. E. C. Aspectos fisiológicos, bioquímicos e agronômicos dos herbicidas inibidores da enzima ALS (AHS). Londrina: Grafmark, 1998. 68 p.

MELO, W.J. Dinâmica das formas de Carbono e de Nitrogênio em um Latossolo Roxo cultivado com Sorghum bicolor (L) Moench e com Dolichos lablab $\mathrm{L}$, isoladamente, ou em cultura intercalada. 1977. 118 f. Tese (Livre docência) - Faculdade de Ciências Agrárias e Veterinárias, Universidade Estadual Paulista, Jaboticabal.
PITELLI, R.; DURIGAN, J. C. Ecologia das plantas daninhas no sistema de plantio direto. In: ROSSELLO, R. D. Siembra directa en el Cono Sur. Montevideo: PROCISUR, 2001; 203-210.

REDDY, K. N.; LOCKE, M. A.; WAGNER, S. C.; ZABLOTOWICZ, R. M.; GASTON, L. A.; SMEDA, R. J. Chlorimuron ethyl sorption and desorption kinetics in soil and herbicide-desiccated cover crop residues. Journal of Agricultural and Food Chemistry, Easton, v. 43, n. 10, p. 27522757, 1995.

REDDY, N. K.; LOCKE, M. A.; GASTON, L. A. Tillage and cover crop effects on cyanazine adsorption and desorption kinetics. Soil Science, Baltimore, v. 162, n. 7, p. 501-509, 1997.

RODRIGUES, B. N. Influência da cobertura morta no comportamento dos herbicidas imazaquin e clomazone. Planta Daninha, Brasília, v. 11, n.1/2, p.21-28, 1993.

RODRIGUES, B. N.; LIMA, J. de; YADA, I. F. U.; FORNAROLLI, D. A. Influência da cobertura morta no comportamento do herbicida trifluralin. Planta Daninha, Botucatu, v. 16, n. 2, p. 163-173, 1998.

RODRIGUES, B. N.; LIMA, J.; YADA, I. F. U.; ULBRICH, A. V.; FORNAROLLI, D. A. Influência da cobertura morta na retenção do imazaquin em plantio direto de soja. Planta Daninha, Botucatu, v. 18, n. 2, p. 231-239, 2000.

SELIM, H. M.; ZHOU, L.; ZHU, H. Herbicide retention in soil as affected by sugarcane mulch residue. Journal of Environmental Quality, Madison, v. 32, n. 4, p. 1445-1454, 2003.

SIGUA, G. C.; ISENSEE, A. R.; SADEGHI, A. M. Influence of rainfall intensity and crop residue on leaching of atrazine through intact no-till soil cores. Soil Science, Baltimore, v. 156, n. 4, p. 225-232, 1993.

THEISEN, G.; VIDAL, R. A. Efeito da cobertura do solo com resíduos de aveia preta nas etapas do ciclo de vida do capimmarmelada. Planta Daninha, v. 17, n. 2, p. 189-196, 1999.

VAN SOEST, P. J. Development of a comprehensive system of feed analysis and its applications to forage. Journal of Animal Science, Champaign, v. 26, n. 1, p. 119-128, 1967. 